Review Article

\title{
Transitioning from Oxime to the Next Potential Organophosphorus Poisoning Therapy Using Enzymes
}

\author{
Rauda A. Mohamed, ${ }^{1,2}$ Keat K. Ong $\mathbb{D}^{1,},{ }^{1,3}$ Noor Azilah M. Kasim $\mathbb{D}^{1,3}$ \\ Norhana A. Halim $\mathbb{D}^{3},{ }^{3}$ Siti Aminah M. Noor $\mathbb{D}^{3}{ }^{3}$ Victor F. Knight $\mathbb{D}^{1,2}$ \\ Nurul Najwa Ab. Rahman, ${ }^{1}$ and Wan Md Zin W. Yunus $\mathbb{D}^{2}$ \\ ${ }^{1}$ Centre for Chemical Defence, National Defence University of Malaysia, Kuala Lumpur 57000, Malaysia \\ ${ }^{2}$ Centre for Tropicalization, National Defence University of Malaysia, Kuala Lumpur 57000, Malaysia \\ ${ }^{3}$ Centre for Defence Foundation Studies, National Defence University of Malaysia, Kuala Lumpur 57000, Malaysia
}

Correspondence should be addressed to Wan Md Zin W. Yunus; wanmdzin@upnm.edu.my

Received 19 April 2021; Accepted 11 August 2021; Published 20 August 2021

Academic Editor: Shafaqat Ali

Copyright (c) 2021 Rauda A. Mohamed et al. This is an open access article distributed under the Creative Commons Attribution License, which permits unrestricted use, distribution, and reproduction in any medium, provided the original work is properly cited.

\begin{abstract}
For years, organophosphorus poisoning has been a major concern of health problems throughout the world. An estimated 200,000 acute pesticide poisoning deaths occur each year, many in developing countries. Apart from the agricultural pesticide poisoning, terrorists have used these organophosphorus compounds to attack civilian populations in some countries. Recent misuses of sarin in the Syrian conflict had been reported in 2018. Since the 1950s, the therapy to overcome this health problem is to utilize a reactivator to reactivate the inhibited acetylcholinesterase by these organophosphorus compounds. However, many questions remain unanswered regarding the efficacy and toxicity of this reactivator. Pralidoxime, MMB-4, TMB-4, obidoxime, and HI- 6 are the examples of the established oximes, yet they are of insufficient effectiveness in some poisonings and only a limited spectrum of the different nerve agents and pesticides are being covered. Alternatively, an option in the treatment of organophosphorus poisoning that has been explored is through the use of enzyme therapy. Organophosphorus hydrolases are a group of enzymes that look promising for detoxifying organophosphorus compounds and have recently gained much interest. These enzymes have demonstrated remarkable protective and antidotal value against some different organophosphorus compounds in vivo in animal models. Apart from that, enzyme treatments have also been applied for decontamination purposes. In this review, the restrictions and obstacles in the therapeutic development of oximes, along with the new strategies to overcome the problems, are discussed. The emerging interest in enzyme treatment with its advantages and disadvantages is described as well.
\end{abstract}

\section{Introduction}

Organophosphates (OPs) are a major class of pesticides used in agriculture. Although OP development started early in the 1930s, its prominence as an insecticide and its further recognition to be lethal for humans as a chemical weapon became prominent in the late 1930s and mid-1940s [1]. OPs inhibit the function of acetylcholinesterase (AChE) and other cholinesterases (ChEs), which lead to nerve impulse damaging and finally incapacitating or causing death to the insect. The primary effects of OPs on humans include acute cholinergic toxicity and a delayed polyneuropathy. Both the insecticides and nerve agents' chemical warfare (such as malathion, chlorpyrifos, tabun, sarin, VX, and soman) react in the same way.

Some OP chemical warfare agents and pesticides are shown in Figure 1. The chemical structure of warfare agents consists of a $\mathrm{P}=\mathrm{O}$ bond, while pesticides consists of a $\mathrm{P}=\mathrm{S}$ bond. OPs with $\mathrm{P}=\mathrm{O}$ bonds are direct $\mathrm{AChE}$ inhibitors, whereas those with $\mathrm{P}=\mathrm{S}$ bonding, which are phosphothioates, do not possess anticholinesterase activities before biotransformation and, thus, are nontoxic by themselves [2]. In 1854, Philippe de Clermont, a French chemist, synthesized the first OP compound tetraethyl pyrophosphate 

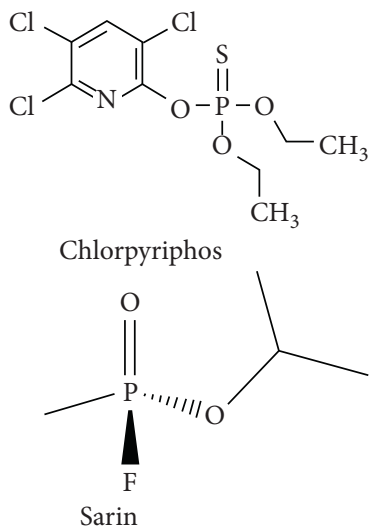<smiles>CCOP(=S)(OCC)Oc1cc(C)nc(C(C)C)n1</smiles>

Diazinon<smiles>CCOC(=O)CC(SP(=S)(OC)OC)C(=O)OCC</smiles>

Malathion<smiles>CCOP(=O)(C#N)N(C)C</smiles>

Tabun

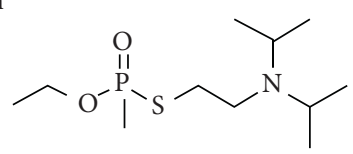

VX<smiles>CC(OP(C)(=O)F)C(C)(C)C</smiles>

Soman

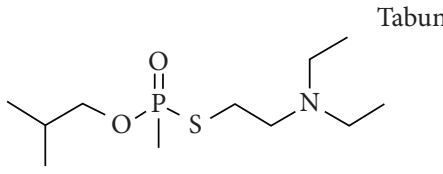

Russian VX

Figure 1: General structure of OP pesticides and chemical warfare agents (structures obtained from https://pubchem.ncbi.nlm.nih.gov/). (a) Chlorpyriphos, (b) diazinon, (c) malathion, (d) sarin, (e) soman, (f) tabun, (g) VX, and (h) Russian VX.

(TEPP) and described it as a phosphor ester [3]. Compounds containing P-F bonds were successfully synthesized in 1932, by Willy Lange at the University of Berlin.

AChE plays an important role in the hydrolysis of the neurotransmitter acetylcholine (ACh), which is found in both peripheral and central nervous systems [4] (Figure 2). The inhibition of AChE is initiated by phosphorylating the serine hydroxyl group on the enzyme. Phosphorylated serine causes the accumulation of acetylcholine, hence over stimulating the nicotinic and muscarinic receptors. The reactivation of inhibited AChE via nucleophilic attack is when the phosphylated group from the OP-AChE adducts is transferred to oxygen from the reactivator. Consequently, the AChE is activated. The mechanism of oxime reactivation is shown in Figure 3. Since the 1950s to date, oximes such as pralidoxime (2-PAM), MMB-4, TMB-4, obidoxime, and HI-6 have been commercialized and successfully treated many cases of OP intoxications [5-9]. However, due to the limitations of oximes, such as unequal effectiveness of their treatment of intoxication by different OPs, aging, and the ability to penetrate the bloodbrain barrier (BBB), the development of oximes to overcome these issues have been carried out extensively.

The development is mainly to focus on the reactivation towards a broader spectrum of OP nerve agents and pesticides, with, more recently, the focus been on the ability to reactivate the AChE in the central nervous system (CNS). Since the chemical structure of OPs determines the reactivation potential, the diversity of chemical structure of OPs is the main issue for reactivation to occur. Nevertheless, there are several commercialized antidotes that have been approved for its broad substrate specificity. For example, methoxime shows to be a good reactivator in case of cyclosarin, sarin, and VX intoxication. For military purpose, HI-6 is preferred since it is able to reactivate almost all nerve agent-inhibited AChE except tabun [10]. Contrarily, HI-6 is unable to reactivate pesticide-inhibited AChE if civilian importance is considered $[10,11]$.
Treatment of OP poisoning is more efficient when the oxime is enabled to reactivate both central and peripheral nervous system AChE. Most of the oximes have low penetration through the blood-brain barrier which is due to the charged molecules resulting in low diffusion ability. Apart from utilizing uncharged oximes which has been found to solve this problem, an interesting alternative is to develop a sugar-oxime conjugate.

To further benefit the treatment of OP poisoning, other adjunctive treatment modalities have been explored. Cohen and Warringa had first proposed the application of enzymes as the alternative approach for the treatment of OP intoxication [12]. Enzymes are biocatalysts that can inactivate OPs in the bloodstream or hydrolyze them into safer metabolites before they can reach AChE at the physiological sites. The application of enzymes can be divided into stoichiometric scavengers, catalytic scavengers, and various types of OPhydrolytic enzymes. There are several advantages and disadvantages of enzyme application in OP poisoning, regarding the time of administration, doses, routes of administration, ease of storage, and distribution to exposed individuals which will be discussed further in this review.

\subsection{Oxime Development Based on Its Chemical Structures and} Its Application in Different Countries. A fundamental comprehension of the specific toxicity of different OPs is a must to develop effective therapies and also in the assessment of the existing antidote restrictions and its medication regimens. Chemical structure of substituents on $\mathrm{P}$ atom of an $\mathrm{OP}$, in addition to the structure of the leaving group, determines the critical ability of the reactivator to reactivates the inhibited AChE. Due to the rigorous production of these OP compounds along with the poisoning issues, for years, oximes have been well established as an antidote for OP intoxication. Starting as early as the 1950s, oximes have been explored (Figure 4). The first oxime was discovered by UK 


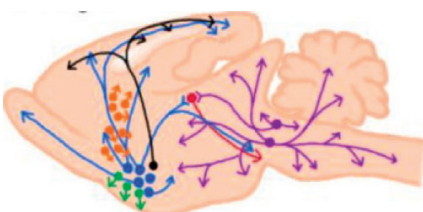

(a)

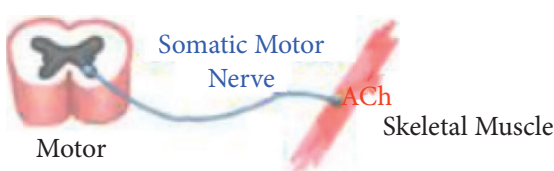

(b)

FIGURE 2: (a) ACh in central nervous systems shown as orange and green cell clusters, limbic structures in blue, and cholinergic projection represented by the black pathway; (b) ACh in the peripheral nervous system (picture adapted from https://nba.uth.tmc.edu/neuroscience/ $\mathrm{m} / \mathrm{s} 1 /$ chapter11.html).

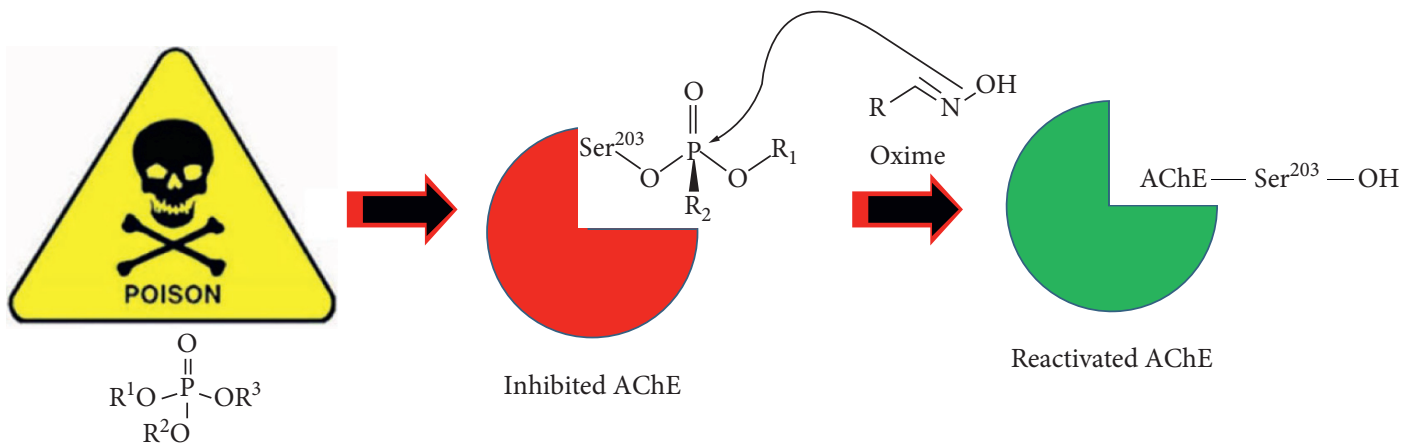

Figure 3: General mechanism of nucleophilic attack from the oxime reactivator towards OP.

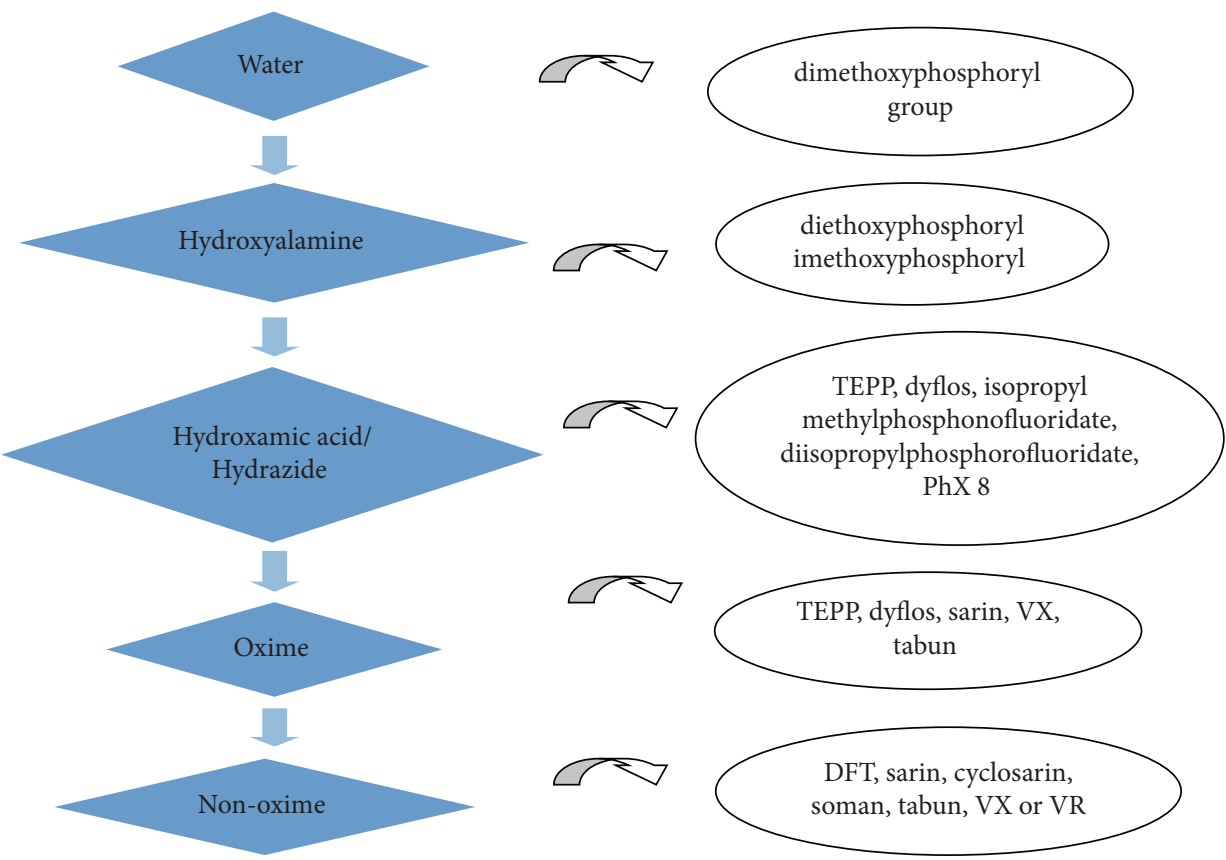

FIgURE 4: The development of OP-inhibited AChE reactivators and some of the inhibitors tested in the reactivation test.

and US research groups, in 1955 [13, 14], who initiated these studies which spearheaded the development of oximes to the present day. They reported that these compounds of a new series are effective antidotes for ChE inhibited by sarin, TEPP, or dyflos in both the rat brain and red cell. The effectiveness of these compounds was reported as superior compared to hydroxamic acids, mostly towards sarin- inhibited ChE. Water, hydroxylamine, and hydroxamic acids were the earlier reactivators tested prior to oximes [15].

As previously mentioned, the initial effort was targeting the charged mono- and bispyridinium oximes. AChE comprises two important sites: the esteric and anionic sites. $\mathrm{OP}$ is attracted to the esteric site and, thus, binds to the hydroxy component of the enzyme, resulting in the 
inhibition of the enzyme. Conversely, oxime is attracted to the anionic site of the enzyme, and due to its oximate ion nucleophilicity, phosphate and serine residue that is covalently bonded is attacked by oxime. The OP then leaves the site and regenerates the enzyme.

The first commercialized oxime 2-PAM is monopyridinium oxime. Strong binding of the positively charged pyridinium towards the enzyme active site and the precise orientation of the oxime group for the phosphyl moiety disruption are the two factors contributing to the effectiveness of the charged oxime [16]. This oxime efficiently reactivates sarin or VX-inhibited AChE [6, 17-21]. 2-PAM iodide given with atropine and diazepam had been used to treat victims during the Tokyo sarin attack in 1995, and its clinical report was very encouraging [22]. Nevertheless, 2PAM was not successful in the reactivation of the tabuninhibited or soman-inhibited enzyme $[23,24]$. Thus, many efforts on the development of novel reactivators to treat tabun and soman poisoning have been carried out. To date, K203 has been nominated as the best treatment for tabuninhibited AChE $[25,26]$, and this reactivator is currently under development [27].

The efficiency of monopyridinium oximes is further improved with the attachment of a ligand that can strongly bind to the AChE, thus orienting the oxime group in the active site [28]. This finding has led to the synthesis of potential bispyridinium oximes between 1959 and 1968. The examples of bispyridinium oximes are MMB-4 (methoxime) and TMB4 (trimedoxime) [29]. Both oximes were reported to be able to reactivate tabun poisoning $[30,31]$. A clinical trial study has been performed for the treatment of parathion poisoning using obidoxime, which is another example of bisquaternary oximes. Obidoxime is the TMB4 analog in which its structure contains one oxygen heteroatom in the bridging alkyl chain in between the two pyridinium rings. The oxime potential is affected by this heteroatom. Obidoxime has been certified as safe and exhibits the potential to reactivate parathion-inhibited AChE [32]. 2-PAM and obidoxime have been introduced into clinical use in the 1950s and 1960s, respectively [33-37].

Since TMB4 shows higher potency compared to monopyridinium oximes, another aldoxime, HI6, has been synthesized as a derivative of TMB4 structure [38]. HI-6 is not effective against all reported nerve agents since its effectiveness depends on the nature of the phosphoryl group of the inhibited AChE. For soman poisoning, HI-6 (asoxime) in combination with atropine is the chosen therapy [39]. HLö 7, the analog of HI-6 which carries two oxime functions in positions 2 and 4 at a single pyridinium ring, had a greater reactivation potential compared to HI-6. Hence, this oxime has been considered as a broad-spectrum oxime and displayed better therapeutic effectiveness towards several nerve agents as well as tabun $[40,41]$. However, since this compound is hard to synthesize, unstable in aqueous solutions, and exhibits higher toxicity, there has been limited interest in the further development of HLö 7. Consequently, HI-6 remains a key for the broad-spectrum candidate [42-44]. Reiner and Rudolph have described the combination of their screening compounds (consisting of pyridinium, imidazolium, and quinuclidinium ring with different substituents and chains linking rings) with atropine to be effective antidotes against the organophosphate nerve agent's tabun or soman. The therapeutic factor $\geq 2.0$ has been shown through animal study [45].

The development of oximes continues for the treatment of aging since 1966 (Figure 5). Pretreatment of aging via AChE effectors is one of the approaches to lower the aging rate since it cause aging retardation [46]. However, these effectors must be consumed before AChE is completely aged. Gallamine triethiodide and propidium iodide are the reported AChE effectors since these compounds act as allosteric ligands of $\mathrm{AChE}$ and bind at a peripheral anionic site [47, 48]. Besides, 2, 4-dimethylimidazole has been reported by Sterri to lower the aging rate by $70 \%$ towards the $\mathrm{AChE}$ inhibited with sarin [49]. These efforts were continued until 2008. Nonetheless, the aforementioned effectors have not been clinically utilized to slow down aging, which might be due to their low activities. The effective concentration of the clinical treatment is on the mM scale, which is too high and may exhibit toxicity [50].

In addition, aged AChE can be realkylated by suitable alkylators which might help in postaging treatments (Figure 6). The alkylators reverse this dealkylation reaction by realkylation of the oxyanion on the phosphoryl adduct. Thus, after realkylation, the negative charge on the phosphoryl group will be neutralized, and the reactivation by oxime reoccurs. The examples of electrophilic alkylating agents include sulfonates, haloketones, methoxypyridiniums, sulfoniums, and quinone methide precursors [51-55].

The other two approaches are by upregulation of AChE expression which can be activated by the exogenous AChE and some peptides. The exogenous AChE can be whole blood or purified AChE, either from human or nonhuman species. However, this approach does not revive aged AChE but may recompense for lowered active AChE levels [50].

The strategies to produce oximes that can penetrate BBB include incorporating oximes with sugar moiety which will be recognized by the facilitative glucose transporters. Hence, these novel sugar-oxime conjugates can be transported across the BBB (Figure 7). Literally, several oximes have been reported to have the ability to penetrate the $\mathrm{BBB}$, for example, sugar conjugated-pyridinium aldoximes in which the sugar conjugated to the pyridine ring $[57,58]$. More recently, $\mathrm{N}$-[(3- $\beta$-d-glucopyranosyloxy) octyl]-2-pyridiniumaldoxime chloride has been synthesized by Garcia et al. and shown to be a potential BBB-penetrating reactivator [59]. This oxime is tested towards AChE and BChE inhibited with $\mathrm{DFP}$, paraoxon, sarin, and VX. The in vitro and in vivo studies of the reactivator show the ability to reactivate the inhibited AChE and BChE from humans, guinea pigs, and mice, either in the blood or CNS. However, it is suggested that high treatment doses may increase the efficiency of the reactivator. The development progress of the BBB-penetrating oxime is slow, and there are no reported novel compounds that are suitable for advanced development or into clinical use [36]. 


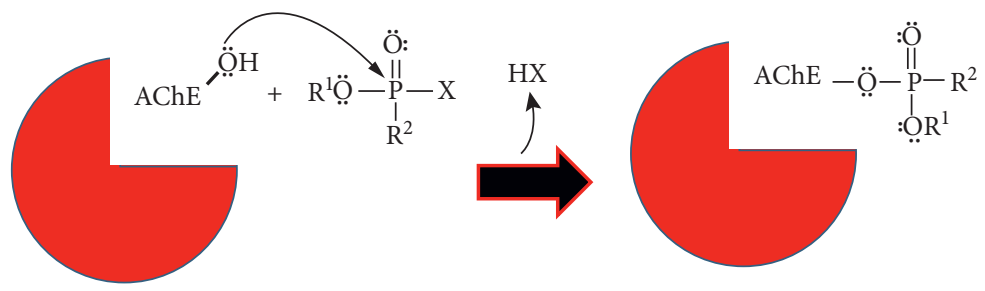

Inhibited AChE

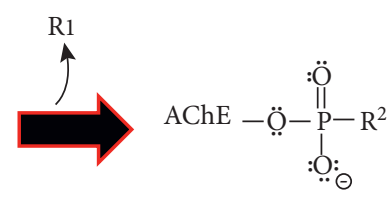

Aged AChE

FIgURE 5: Scheme illustrating aging of AChE.<smiles>[R]c1cccc(OCC)c1</smiles><smiles>[R]n1ccccc1=O</smiles><smiles>COP(C)(=O)OC</smiles><smiles>[R]c1cccc(OC)c1CCOP(C)(=O)OC</smiles><smiles>C[In]1CCCCC1</smiles><smiles>[R]C1CC=CC(COP(C)(=O)OC)(OCC)N1[R]</smiles>

Figure 6: The alkylation of aged AChE with methoxypyridiniums. Two possible mechanisms of methyl transfer from methoxypyridiniums to phosphonates were proposed in [51]. Pictures were adapted from [50].

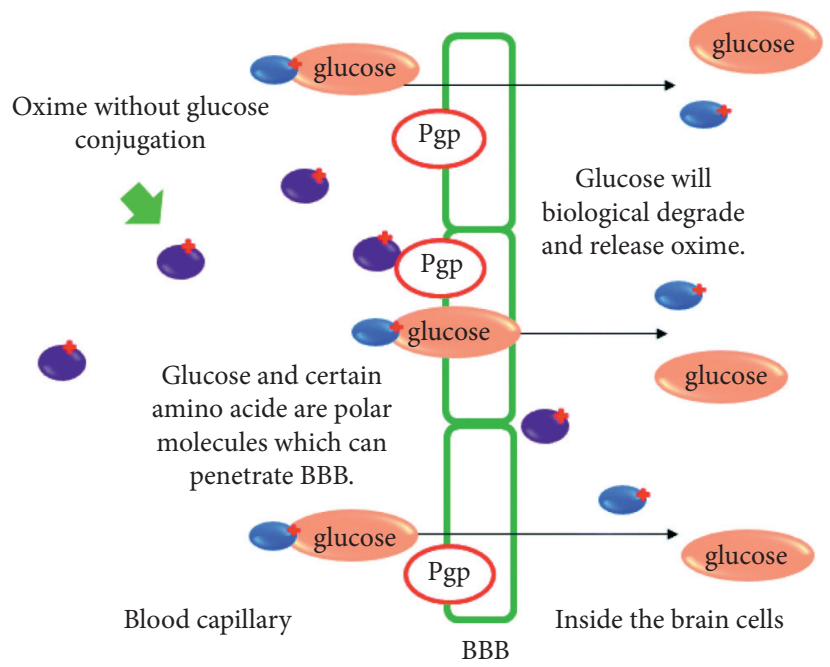

Figure 7: Schematic diagram of BBB penetration of glucose-conjugated oxime. The picture was adapted from [56].

The searching and exploration of enhanced uncharged oximes with the ability to reactivate human AChE are still needed $[60,61]$. Recently, seven candidates of uncharged acetamido bis-oximes have been synthesized as reactivators [62]. Bis-oximes consist of two oxime groups that are connected to the same central, saturated heterocyclic core. Diverse protonation of the heterocyclic amines and oxime groups of these bis-oximes lead to the equilibration up to 16 different ionization forms. The compounds are in uncharged forms that can penetrate the CNS and also numerous zwitterionic forms optimal for the reactivation to occur [62]. They modified these bis-oximes from the X-ray structures of the monoxime RS194B reversibly bound to native and VXinhibited human AChE (hAChE) [62]. Previously, the potential of a novel zwitterionic and centrally acting oxime RS194B to reactivate sarin- and paraoxon-inhibited 
macaque AChE and butyrylcholinesterase (BChE) has been successfully tested in vitro and in vivo [62].

The improvement of the reactivation potential was in agreement with the prolific position of one of the two nucleophilically reactive aldoxime groups. Additionally, the dynamic charge distribution and the correct binding orientation between the three or four ionizable groups of the novel heterocyclic bis-oxime leads to better diversity of the zwitterionic forms which are supposed to be mostly in charge of the nucleophilic reactivation of OP- $h$ AChEs.

A recent study by Zorbaz et al. has reported the efficiency of bispyridinium oximes with one (K865, K866, and K867) or two (K868, K869, and K870) ortho-positioned chlorine moieties, to reactivate human butyrylcholinesterase (BChE) inhibited by sarin, cyclosarin, VX, and tabun [63]. These compounds are similar to the previously known K027, K048, and K203 oximes which are potent reactivators of human AChE inhibited by nerve agents. With their ability to reactivate both $\mathrm{AChE}$ and $\mathrm{BChE}$, these compounds have the potential of pseudocatalytic scavenging of most nerve agents.

As it was described many times, there are only few commercially available AChE reactivators on the market: pralidoxime (2-PAM; P2S; and 2-hydroxyiminomethyl-1methylpyri-dinium chloride or methansulphonate), trimedoxime $\left(\right.$ Fosan $^{\circledR}$, , 1, 3-bis (4-hydroxyiminomethylpyridinium)-propane dichloride or dibromide), obidoxime (Toxogonin ${ }^{\circledR}$; LüH-6; 1,3-bis(4-hydroxyiminomethylpyridinium)-2-oxapropane dichloride), methoxime (MMC-4; MMB-4; and 1, 1-bis (4-hydroxyiminomethylpyridinium)methane dichloride or dibromide), and HI-6 (1-(2hydroxyiminomethylpyridinium)-3-(4-carbamoylpyr-

idinium)-2-oxapropane dichloride or dimethanesulfonate). Although thousands of oximes have been investigated and developed from 1955 to date, only few oximes are applied for clinical purposes or advanced development. An improved reactivator with a closer and more critical approach to the oxime concept along with the factors determining its in vivo effectiveness is needed.

The application of oxime varies between countries. For example, in the USA, 2-PAM $\mathrm{Cl}$ is a licensed oxime. However, most of Europe and Iran preferred obidoxime as their licensed oxime [64]. Iran used this oxime in small quantities. Due to the carcinogenic intermediate being formed during the synthesis process of obidoxime, this oxime is not licensed in the USA. TMB-4 is preferred in Israel while Canada is in the middle of changing its licensed 2-PAM Cl to HI-6. Rather than using 2-PAM Cl, Japan preferred 2-PAM iodide due to cultural reasons. Thyroid disease with a high baseline rate predisposes physicians to treat with iodides where feasible. A higher dosage of 2-PAM $\mathrm{Cl}(\geq 2000 \mathrm{mg}$ ) can also trigger dangerous hypertension; thus, in the USA, this oxime can only be found at poison control centres [65]. Atropine alone is used if there is a need for prolonged treatment during that time.

1.2. Limitations of Oxime Therapy for OP Poisoning. Several factors contribute to the challenges of using reactivators as a treatment in $\mathrm{OP}$ poisoning. Firstly, the probability of the presentation's differences in the acute toxicity symptoms of both aliphatic and aromatic OP pesticides as well as their phosphyl moiety has not been fully understood yet. Secondly, AChE's side chains and aromatic rings may present structural and thermodynamic properties disadvantageous towards current and next therapeutic modalities. This has become a subject of concern, and consequently, new therapeutic is hard to develop.

Apart from that, the stability of the reactivation intermediate product has also been an issue. Generally, in some cases, AChE reactivation has resulted in the stable production of phosphoryloxime intermediate which inhibits $\mathrm{AChE}$ at higher rates compared to the parent oxons and is eliminated gradually. However, this condition is likely to occur towards 4-pyridinium aldoximes in comparison to the phosphoryloximes from 2-pyridinium aldoximes which is easily altered [34]. Another limitation of oximes, specifically 2-PAM, is that this oxime is not a broad-spectrum antidote and is restricted in its usage against $\mathrm{OP}$ toxicity, either from OP pesticides, OP chemical weapon agents, OP chemicals (only those with anticholinesterase activity), or cholinesterase inhibitors.

While oximes cannot penetrate the BBB, even with the latest design of oxime, OP nerve agents can simply do so [65]. Even with the latest strategy to enhance the lipophilicity of oximes by structural modifications, the attempt was only successful via in vitro study. Based on in vitro results, K869 oxime exhibits slightly higher effective permeability values in the parallel artificial membrane permeability assay (PAMPA). However, further in vivo evaluation shows the penetration of the oxime towards BBB recorded only a small amount of oxime ( $60 \mathrm{ng} / \mathrm{g}$ of tissue) was found in the brain about 30 min after oxime administration. The penetration of K869 into the brain did not exceed conventionally used oximes since the brain/plasma ratio calculated is less than $1 \%[66]$.

Hence, oxime primarily acts at nerve junctions and works best to reverse the paralysis of respiratory muscles but does not affect centrally mediated respiratory depression. As a consequence, 2-PAM is administered together with atropine which can penetrate the $\mathrm{BBB}$. During the treatment of $\mathrm{OP}$ poisoning, atropine is given before the administration of 2-PAM since atropine can antagonize the muscarinic effects of OPs. The efficiency of atropine in OP poisoning is well established compared to 2-PAM where its clinical use is still being researched to improve its ability to provide therapeutic relief.

Throughout this period, broad research efforts have led to the preparation of unlimited experimental oximes and, more recently, certain nonoxime reactivators. The intention is to use as a substitute or as an adjunct to the established and licensed oximes. However, none of them are yet to be manufactured. New oxime's structure, uncharged oximes, conjugation of uncharged oximes, and sugar-oxime moieties are among several strategies to increase the BBB penetration efficiency of oximes [61]. It has been reported that oximes get access into the brain and, thus, reactivate inhibited local AChE. Even the oximes in the central nervous system exhibit significantly lower concentration than in the plasma, and 
they can reduce the effect of OP-induced brain using other than the AChE reactivation method of action. The method of action might involve centrally neuroprotective mechanisms.

In some cases, 2-PAM is attracted to the aromatic residues of inhibited $\mathrm{AChE}$ in the nonproductive configuration to reactivate $\mathrm{AChE}$, while the structural diversity of OPs hinders the effective reactivation [56]. To overcome this problem, the reactivators should be improved to optimize its nucleophile within the AChE active-center gorge. An example of the reactivator that has been reported to overcome the nonproductive configuration issue of oxime is the aforementioned monoxime RS194B.

Another issue that is of concern is an effect called "aging" which is the result of the OP-inhibited AChE that has undergone dealkylation reaction. The dealkylation reaction can follow inhibition, thus producing an oxyanion on the phosphoryl group [50]. Due to this aging event, the oxime must be administered before this event occurs. There is no clinically relevant spontaneous reactivation of AChE occurring before aging has occurred in the case of soman poisoning since the aging occurs so fast. In other words, resynthesize of $\mathrm{AChE}$ is the only way to recover the function. Consequently, it is a must that an oxime is administered quickly after soman exposure so that some reactivation of AChE occurs before all the enzymes become aged [67]. However, in cases of acute OP poisoning, even when the oxime is administered before AChE aging is thought to occur, the clinical benefits are not very encouraging [34, 67]. Therefore, it is vital to develop new therapies for patients presenting severe OP poisoning. Each nerve agent has a different period of aging. Several aging side reactions are very slow that they can be clinically eliminated. The aging halftime of VX, sarin, tabun, and soman is 40 hours, 3-4 hours, 13-14 hours, and 2 minutes, respectively [68]. Consequently, if the patient is poisoned by soman, oxime therapy is useless unless the patient is given treatment directly. Efforts to replace 2-PAM with more efficient AChE reactivators by the United States and other countries are ongoing, but there are none that are close to FDA approval.

Although new improved oximes are needed to treat OP poisoning, the assortment and applications of novel oximes encounter several problems. Usually, intentional intoxications of OP pesticide happen in developing countries facing limited financial resources $[69,70]$. Notwithstanding the number of patients requiring effective medical treatment is extremely large, the continuing controversy on the virtue of oximes [67, 71], the effort in designing meaningful phase II clinical studies [70], and the hesitancy of the pharmaceutical industry to involve in oximes hinders a wider and optimized use of the recognized oximes 2-PAM and obidoxime. Hence, the intensified research on improved reactivators against $\mathrm{OP}$ pesticides is unlikely.

Several cases of OP poisoning involved the ingestion of OP pesticides in large quantities, thus resulting in very high OP concentrations in blood. The ingested OP is spread to the entire body with the highest amount being stored in fat-rich tissues [72]. Usually, several weeks after OP exposure and adsorption, this OP will leach out from the fatty tissues. The leaching of OP from this stored fat will eventually cause serious issues to treat the severe $\mathrm{OP}$ poisoning victims as the $\mathrm{OP}$ will return into the blood circulation. Consequently, OP continues to inhibit $\mathrm{AChE}$ at the neuromuscular junctions throughout the body. Besides, due to the lipid reservoir of pesticide, patients frequently need to continue 2-PAM therapy for several weeks after they ingest pesticides with the highly lipophilic property such as diazinon.

Based on the cohort study of patients poisoned with dimethoate in Sri Lanka, it is proven that patients with blood dimethoate concentrations of above $750 \mu \mathrm{M}$ cannot survive, regardless of maximal conventional therapy with oximes [73]. It is assumed that the degradation or functional inhibition of the ingested OP will decrease the blood OP concentrations, thus allowing a higher percentage of patients to survive. This prolonged deposition of $\mathrm{OP}$ in body tissues is one of the factors highlighting the importance of the enzymatic degradation of OPs.

\subsection{Applications of Enzyme Therapy for OP Poisoning and Its} Limitations. The emerging of two unique protein classes in the treatment of OP poisoning such as stoichiometric bioscavengers that can trap OPs and catalytic bioscavengers which can degrade OPs has started in early 1957. These enzymes were particularly studied since they allow effective detoxification and decontamination without toxicity or environmental impact [74]. Apart from that, bioscavengers also have a rapid and wide range of actions towards a variety of toxic OPs including sarin, soman, and tabun [75]. They are readily absorbed from the injection sites and exhibit extended circulatory retention time [76]. A combination treatment for skin decontamination in which OP hydrolases are incorporated with oxime is preferred to detoxify all phosphonylated oximes with little substrate specificity [77].

Catalytic bioscavengers are capable in hydrolyzing OPs in a relative high turnover which indicates better protection compared to large doses of costly low-activity enzymes. An OP-hydrolytic enzyme is widely used in detoxification, for example, phosphotriesterases (PTE) and glutathione-Stransferases (GST) [78, 79] (Figure 8). The importance of PTE towards the toxicity of OP insecticides has been discovered to be critical as its activity can drastically influence the toxicity. The destruction of diazinon, on the other hand, is carried out by glutathione S-transferase [80-86]. The hydrolysis products of this reaction are the nontoxic metabolites glutathione conjugate S-(2-isopropyl-4-methyl-6pyrimidinyl) glutathione and diethylphosphorothioic acid.

A test on the ability of OpdAs to hydrolyze OP insecticides in the sample consisting human serum and clinically appropriate minipig models has been carried out [87]. The results show that the hydrolysis rate between 856 (SD 44) down to 0.107 (SD 0.01) moles of substrate hydrolyzed/mole of enzyme/sec (kcat) for quinalphos and phenthoate has been achieved, respectively. The highly efficient production of all the aforementioned enzymes from this prokaryotic system leads to the idea of producing it commercially such as streptokinase. However, due to the consequent risk of unfavourable reactions and immunogenicity, the subsequent application in humans will be limited over the next 12 


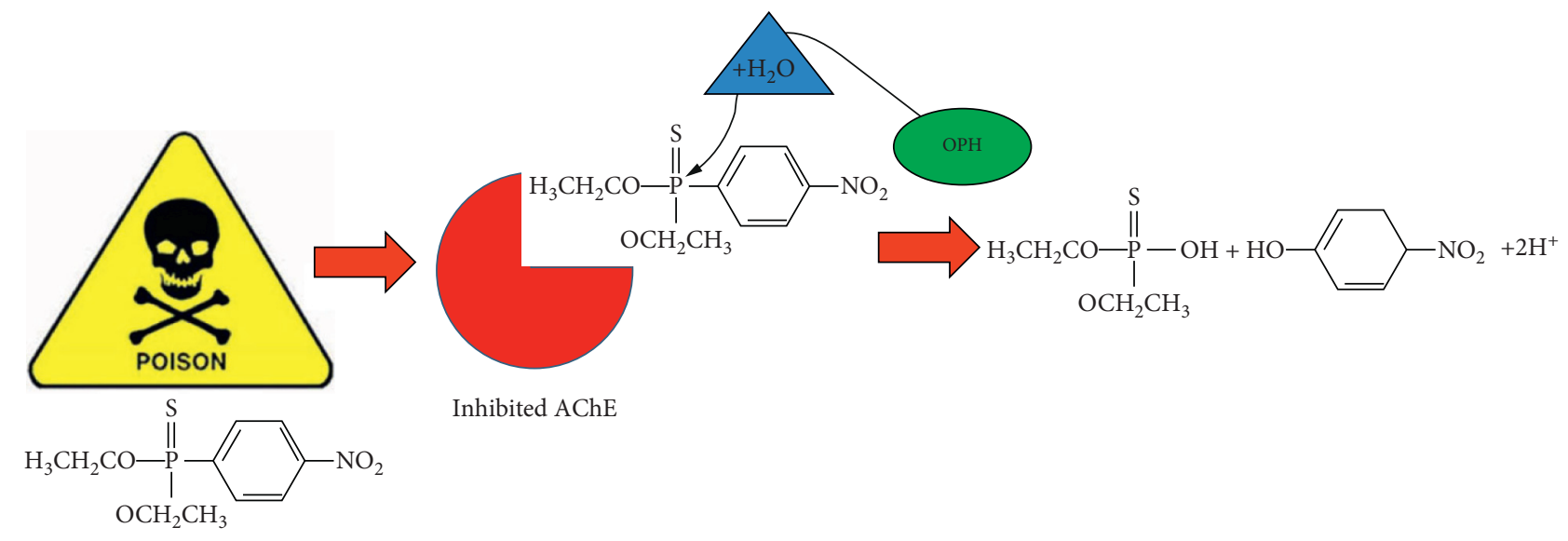

FIGURE 8: Schematic of OP insecticide hydrolysis by OP hydrolases. The products of hydrolysis do not inhibit acetylcholinesterase.

months [88]. Before clinical use, some parameters such as human safety, immunogenicity, and tolerance must be tested.

Plasma paraoxonase-1 (PON1) is one of the examples of OP-hydrolytic enzymes in human plasma. To increase its efficiency against OPs, this enzyme has been mutated at the catalytic site as what has been reported by Kirby et al. [89]. The hydrolysis activity of PON1 has improved 9-fold compared to its native. Nevertheless, the absence of a proper hydrophobic environment affects the catalytic efficiency. Thus, for immune acceptance and half-life modulation, PEGylation is needed.

OP acid anhydrolase $(\mathrm{OPH})$ is originated from Alteromonas undina. This enzyme with a molecular weight of $53,000 \mathrm{kDa}$ composed of a single polypeptide chain has been successfully purified [90]. The substrate for OPH, diisopropylfluorophosphate, is hydrolyzed with a specific activity of $\sim 575 \mu \mathrm{mol} / \mathrm{min} / \mathrm{mg}$ of protein with its optimum activity at $\mathrm{pH} 8.0$ and $55^{\circ} \mathrm{C}$ by this OPH. This enzyme prefers sulfhydryl reducing agents and manganese as its inducer.

The important of enzymatic degradation of OP is also applied in foodstuffs. As what we acknowledge, in order to control agricultural and domestic pests, organophosphorus pesticides (OPPs) are widely used. Through consumption of contaminated foods and water, the exposure towards OPP residues poses serious health threats to human health. Hence, the removal of the OPP residues from foodstuffs to enhance food safety is required. Probiotic microorganisms in contaminated foodstuffs have also been claimed to exhibit the functional capacity to degrade pesticides. A review by Sarlak et al. has provided the interactions between different OP pesticides (OPPs) and phosphatase from probiotics in various food and organism models. The toxicity and gut absorption of OPPs are decreased in food supplemented with probiotic strains via binding and/or metabolizing mechanisms. Mechanisms of action used by probiotics against OPPs are mostly associated to phosphatase capability. However, lactic fermentation by probiotics that can exclusively be used in fermented foods is crucial in this biological detoxification. Therefore, factors such as inoculated probiotic levels, initial pesticide concentrations, fermented food types, and environmental conditions on bioremediation activity of probiotics are important to be further investigated [91].

The second group is cholinesterases and other related enzymes in which these enzymes stoichiometrically bind and neutralize OP. This group of enzymes that act naturally to defend our body from OP intoxication is known as stoichiometric bioscavengers. They naturally and sufficiently protect low exposure doses of OP but ineffective for highdose exposition [92]. These specific molecules irreversibly bind to pesticide OP in a mole-to-mole ratio. Human butyrylcholinesterase is the most advanced stoichiometric bioscavenger and known as pseudocholinesterase and it is found in the liver and plasma (Figure 9). Although the administration of exogenous butyrylcholinesterase can protect humans, however, by increasing the amount of the administered enzymes, certain metabolic processes or enhanced immunogenic reaction will occur. For that reason, protection such as PEGylation or the inclusion of these enzymes in nanocontainers should avoid immune responses.

Larger doses of these stoichiometric bioscavengers have been proven to act efficiently against soman and VX [93, 94]. Since the effective required doses are highly expensive, production of human butyrylcholinesterase on a larger scale has become the main focus.

Hence, this enzyme has been produced in a recombinant form. Unfortunately, the plasma half-lives of the recombinant butyrylcholinesterase are shorter as compared to its native form. Several studies are conducted to overcome this issue such as PEGylation, addition of peptides and fusion to albumin [95, 96]. PEGylation is also useful for protein stability.

Human butyrylcholinesterase (r-HuBuChE; PharmAthene Inc.), which has been successfully produced in a recombinant form and expressed in the milk of transgenic goats, has become commercially available. This recombinant form of $\mathrm{r}-\mathrm{HuBuChE}$ is similar biochemically to plasmaderived $\mathrm{HuBuChE}$ through in vitro assays. The pharmacokinetic properties of polyethylene glycol coated (pegylated) form of $\mathrm{r}-\mathrm{HuBuChE}$ were administered to guinea pigs. From the observation, it was found that the enzyme's half-life ( $t$ (1/ 


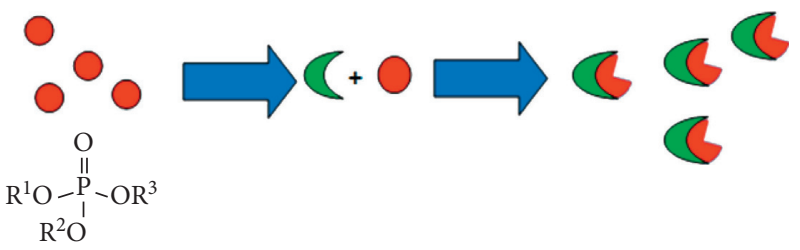

FIGURE 9: Schematic diagram of the stoichiometric bioscavenger mechanism. The red circle represents nerve agents, and the green represents the scavenger.

2)) and pharmacokinetic profile resembled that of plasmaderived $\mathrm{HuBuChE}$ and were rapidly bioavailable [97]. Therefore, in future studies, it is not possible to design a mutant form of $\mathrm{HuBuChE}$ with improved activity and stereospecificity towards the most toxic nerve agent isoforms.

Many studies on the successful application of human butyrylcholinesterase (E.C. 3.1.1.8) in providing a stoichiometric nature of the shield in humans against $\mathrm{OP}$ nerve agents have been reported [90, 98, 99]. Butyrylcholinesterase has shown the ability to protect up to five and a half times the median lethal dose of OP nerve agents in several animal models. This enzyme has been purified from blood plasma and has been given to animals $(26.15 \mathrm{mg} / \mathrm{kg} \equiv 308 \mathrm{nmol} / \mathrm{kg})$ by the intravascular or intramuscular route prior to either soman or VX uptake. This resulted in the increment of the median lethal dose of soman from $154 \mathrm{nmol} / \mathrm{kg}$ to $770 \mathrm{nmol} /$ $\mathrm{kg}$ using $308 \mathrm{nmol} / \mathrm{kg}$ of human butyrylcholinesterase. Besides, this enzyme was also shown to successfully increase the median lethal dose of VX from $30 \mathrm{nmol} / \mathrm{kg}$ to $312 \mathrm{nmol} /$ $\mathrm{kg}$ [99]. There were reported enzymes that have been proposed for specific enzymatic treatments such as direct enzyme injection, liposome and erythrocytes carriers, PEGylated preparations, and extracorporeal enzymatic treatments [100].

Carboxylesterases (CarbE, EC 3.1.1.1) is another example of stoichiometric bioscavengers. Malathion and some other OPs are carboxylic acid esters. The toxicity of these OPs in mammals is very low due to the very high activity of carboxylesterases in different tissues of mammals. CarbE can hydrolyze esters of carboxylic acids which are the essential pathways to detoxify malathion and its toxic metabolite malaoxon [101, 102].

Apart from detoxification, enzymes for decontamination towards OPs have been developed using several different approaches which include chemical, physical, and biological decontamination. Enzyme treatment is one of the biological decontamination methods that have been applied [103]. Due to the stability issue in enzymes, the application of enzymes in decontamination is usually incorporated with immobilization strategies. Validated enzyme decontamination with its immobilization strategies are summarized in Table 1. There is emerging interest towards enzyme for OP decontamination which used a biocatalyst, namely, SsoPox, which has been isolated from Sulfolobus solfataricus (archaeon). The SsoPox was first described by Merone et al. [104]. Being hyperthermostable, this enzyme appears to be interesting enough to be applied as external decontamination for its stability and catalytic efficiency. Efforts to engineer this enzyme for detoxifying a broad spectrum of toxic OPs are ongoing [105].

The OpdA gene was previously isolated in Agrobacterium radiobacter $\mathrm{P} 230$ by Horne et al. [105]. Several in vitro studies have been performed as well as its use in a field trial $[105,106]$. For example, a decontamination test towards $84,000 \mathrm{~L}$ of water from an agricultural site polluted with methyl parathion was performed, in which the OpdA successfully fixed to a matrix structure was able to clear $>90 \%$ of methyl parathion in a fast-water-flow passage in just 10 minutes [107]. An in vitro study shows this enzyme exhibits very high activity towards a broad range of pesticides that may be involved in human poisoning cases [87, 108].

Apart from the aforementioned ability of $\mathrm{OPH}$ in detoxification, this enzyme is also nominated as a perfect enzyme for bioremediation of insecticidal OPs with a rate that closes to the diffusion limits [90]. It can also degrade a broad range of nerve agents and some chromogenic phosphinates. Similar to OPH, PTE also has the ability to effectively degrading OP pesticides and G-series nerve agents such as soman, thus showing that PTEs have the potential to be both a therapeutic agent and an environmental decontaminant. Another group of PTE enzymes, OpdA (aryldialkylphosphatase) (EC 3.1.8.1), has also been proven to be useful for the environmental cleansing of OP insecticides and has been found to prevent death among rats and nonhuman primate models if given directly after exposure.

Most of the nerve agents contain a chiral phosphorus center with the SP-enantiomers being significantly more toxic than the RP-enantiomers. PTE which exhibits the ability to detoxify these OP, however, has the stereochemical preference for the RP-enantiomers. Thus, the designation of PTE mutants has been developed to test their hydrolysis ability towards a series of these OP enantiomerical analogs containing the relevant phosphoryl centers. Interestingly, some of the mutants with significantly enhanced, as well as relaxed or reversed, stereoselectivity have been reported [109].

The third group is pseudocatalytic, which is a mixture of ChE and oxime pretreatment [110] (Figure 10). When enzymes react with OPs to form a covalent adduct, in the presence of reactivators, it can act as a catalytic bioscavenger if both phosphylation and reactivation are together. However, the most important rule is the reactivation must occur before aging. Kovaric et al. have reported a study using this pseudocatalytic approach via in vitro reactivation of phosphorylated human plasma BChE [111]. They used bispyridinium oximes differ in the length and type of the linker between rings and the position of the oxime group on the ring. K117 [1, 1- $(2,2$ oxybis (ethane-2, 1-diyl)) bis (4-hydroxyiminomethyl pyridinium) bromide] and K127 [4-carbamoyl-1-(2-(2(4-(hydroxyiminomethyl) pyridinium-1-yl) ethoxy) ethyl) pyridinium bromide] show potent reactivators for tabun-inhibited BChE at $1 \mathrm{mM}$ after only $20 \mathrm{~min}$ of reactivation. However, reactivation of $\mathrm{BChE}$ inhibited with paraoxon by all selected oximes was slow.

Other than HI-6, the efficacy of current oximes is narrow and oxime-induced reactivation of ChEs (human BCHE) is 
TABle 1: Validated decontamination and detoxification approaches using enzymes.

\begin{tabular}{|c|c|c|}
\hline Authors & Enzyme and matrix for immobilization & Application \\
\hline Caldwell and Raushel, 1991 & $\begin{array}{c}\text { PTE from Pseudomonas diminuta onto the trityl } \\
\text { agarose matrix }\end{array}$ & $\begin{array}{l}\text { Detoxify various OPs with higher affinity towards } \\
\text { paraoxon }\end{array}$ \\
\hline Raynes et al., 2011 & $\begin{array}{l}\text { PTE from Pseudomo } \\
\text { fibrils generated } \mathrm{f}\end{array}$ & $\begin{array}{r}\text { Detoxify various OPs wi } \\
\text { para }\end{array}$ \\
\hline Gao et al., 2014 & $\begin{array}{r}\text { OpdA from using covalent in } \\
\text { polyester text }\end{array}$ & $\begin{array}{l}\text { Effectively degrades org } \\
\text { environmental remec }\end{array}$ \\
\hline $\begin{array}{l}\text { Suth } \\
\text { Nage }\end{array}$ & PTE from Pseudo & $\begin{array}{l}\text { Detoxify various OPs with higher affinity towards } \\
\text { paraoxon }\end{array}$ \\
\hline Mechrez et al., 2014 & $\begin{array}{l}\text { PTE from } D \text {. radiodurans onto carbon nanotube } \\
\text { paper }\end{array}$ & $\begin{array}{l}\text { Environmental remediation of biomedical devices } \\
\text { (decontamination) }\end{array}$ \\
\hline
\end{tabular}

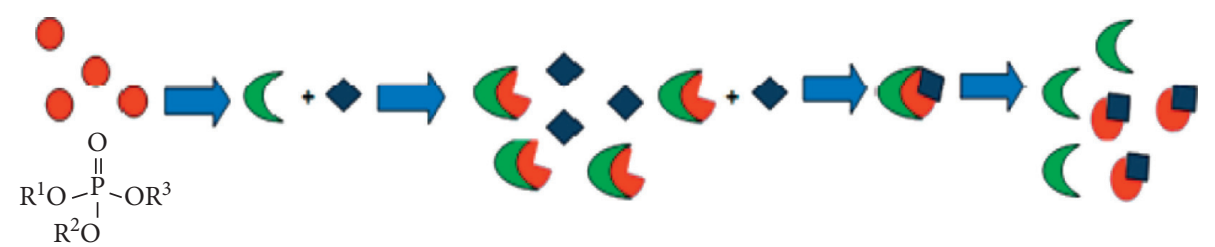

FiguRE 10: Schematic diagram of the pseudocatalytic mechanism. The red circle represents the nerve agent, green represents the scavenger, and dark blue represents oxime.

slow for the pseudocatalytic scavenging of OP molecules' efficiency [112]. In contrast, as reported by Sit et al. [113] and Kovaric et al. [114], new imidazole aldoximes show to be promising reactivators for $\mathrm{OP}$-inhibited $\mathrm{AChE}$. The currently designated mutant of AChE, namely, Y337A/F338A, which does not age after phosphylation shows effective potent pseudocatalytic bioscavengers. Another reactivatable serine hydrolase such as human CaE-1 is also found to be of potential interest [115]. Overall, good bioscavengers must have these fundamental properties which are prolonged circulatory residence time and the absence of antienzyme antibodies following repeated injections [110].

$$
x=\frac{-b \pm \sqrt{b^{2}-4 a c}}{2 a} .
$$

1.4. Future Directions in the Treatment of OP Poisoning. Several different structural elements were incorporated into the oxime structure cumulating in uncharged oximes and nonoxime reactivators as recent strategies to develop reactivators that can penetrate BBB [116-119] (Figure 11). These reactivators should further investigate since they show a very promising value of antidotes. Another promising approach is to apply specific BBB transporters such as P-glycoprotein (Pgp) inhibitors and nanoparticles as drug carrier which has also been reported [120]. Due to the inadequate reports focused on the application of these approaches for oximes, the Pgp inhibitors and nanomaterial carriers for oxime delivery into the CNS need to be further studied in the future [61].

Apart from targeting the BBB-penetrating oxime, aging treatment is also one of the researchers' targets for future reactivator development. For aging treatment, Fas2-AChE chimeric proteins were proposed. This Fas2 moiety can anchor the protein to the NMJ and synapses, where endogenous native AChE is naturally located [50]. This work seems to be promising for the development of a new reactivator.

The future direction on the enzymatic treatment is towards the chemical scavengers which have been shown recently with the synthesizing of bifunctional oximehydroxamic acid hybrid molecules. These scavengers were proven in vivo to protect rat against sarin [121]. However, nearly all chemical scavenger systems depend on functionalized cyclodextrin-bearing nucleophile groups that degrade OP directly with a moiety that reactivates AChE inhibited by OP [122]. Their mechanism has been studied and shows that they belong to the stoichiometric scavenger family $[123,124]$. They conclude that based on the in vivo data, some hybrids may serve as efficient small-molecule scavengers for mitigating the toxicity of OP nerve agents. Nevertheless, these OP-hydrolyzing catalysts appear more suitable for external decontamination at the moment. However, their usage in the future as economical and universal scavengers is not unimaginable [125].

Another point of view is due to the increments in genomic sequencing and cataloging of environmental microbes, new enzymes and novel pathways will be easier to obtain by researchers for the bioremediation of OPs and other environmental contaminants. By applying molecular biology tools and protein design, researchers have the opportunity to alter these enzymes to increase the substratebinding ability and catalytic activity. Both current and future OP hydrolases are predicted to be developing due to these rapidly fundamental studies. The commercialization of these enzymes involves large-scale production with high costs, manufacturing, and stabilization. Although these factors have continuously being argued, Novozyme, Gingko Bioworks, and other companies continue to demonstrate the attainability and profitability of enzyme commercialization. 
<smiles>CC(C)(COCC(C)(C)N1CCC(OC(c2ccccc2)c2ccccc2)CC1)C[n+]1ccc(/C=N/O)cc1</smiles>

Compound 1<smiles>CC(C)(COc1ccc(C(=O)/C=N/O)cc1)OCC(C)(C)N1CCC(OC(c2ccccc2)c2ccccc2)CC1</smiles>

Compound 3<smiles>COc1cc2c(cc1OC)C(c1ccccc1)N(CCCCc1ccc(O)c(/C=N/O)n1)CC2</smiles>

Compound 5<smiles>CCN(CC)Cc1cc(N)ccc1O</smiles>

Compound 7<smiles>CCC[NH+]=C(C=NO)N(C)C</smiles>

Compound 2<smiles>O=C(/C=N/O)NCCN1CCCCCC1</smiles>

Compound 4<smiles>N=Cc1nc(CCCCNc2c3c(nc4ccc(Cl)cc24)CCCC3)ccc1O</smiles>

$\mathrm{OH}$<smiles>Nc1ccc(O)c(CN2CCCC2)c1</smiles>

Compound 8

Figure 11: Example of uncharged oxime and nonoxime reactivators. Compounds 1-6 show primarily oximes, while 7-8 show nonoxime reactivators. Pictures were adapted from [36].

Since these companies have been backed up by financial companies and others, it is indisputable that the potential of biological systems has been recognized.

Apart from oximes and enzymes, very recent approach on the toxicity breakdown of OP using the photocatalytic approach has been carried out. A recent study from Filho et al. has proven the degradation of methyl parathion (nerve agent simulant) by a visible photocatalytic $\mathrm{NbOFe}$ nanofabric (NbOFe-NF) which has been produced by electrospinning solvent suspension of an iron niobate photocatalyst and polycaprolactone (PCL). After methyl parathion has been exposed to visible radiation for $48 \mathrm{~h}, 94.52 \%$ conversion has been achieved. The advantages of NbOFe-NF are the selectivity for the production of less toxic compounds in which it only cleaves the P-O-Ar system and the demethylation of DMPP by the nanofabric generates nontoxic compounds. This detoxifying process is wholly via photocatalysis, through $h^{+}$and $\mathrm{O}^{\circ} \mathrm{H}[126]$.

\section{Conclusions}

Both oxime and enzyme therapies for OP poisoning are important depending on the circumstances. Although oximes are proven to effectively preventing lethality from $O P$ poisoning, postexposure convulsions, incapacitation, performance deficits, or, in some cases, permanent brain damage are not taken into account. These problems give rise to the development of bioscavengers as a pretreatment to cleave off highly toxic OPs before they get to their physiological targets. In conclusion, it can be seen that extensive studies of both oxime and enzyme therapy for OP poisoning have had a large contribution toward global health issues to date. Oximes remain to have potential as a reactivator for $\mathrm{AChE}$ in OP poisoning with the added benefit of being cheap to produce and easy to obtain. Nevertheless, enzymes also show great potential before further exploration as an antidote. However, it has a higher cost and a tedious process for the production of these enzymes, apart from laborious and 
the administration of those enzyme proteins into OP exposed individuals. Hence, further research is necessary to overcome these issues.

\section{Data Availability}

The data used to support the findings of this study are available from the corresponding author upon request.

\section{Conflicts of Interest}

The authors declare no conflicts of interest regarding the publication of this paper.

\section{Acknowledgments}

This work was supported by the Ministry of Education, Malaysia, under Grant UPNM/2018/CHEMDEF/ST/01.

\section{References}

[1] L. G. Costa, "Organophosphorus compounds at 80: some old and new issues," Toxicological Sciences, vol. 162, no. 1, pp. 24-35, 2018.

[2] B. Balali-Mood, "Chemistry and classification of OP compounds," in Basic and Clinical Toxicology of Organophosphorus Compounds, pp. 1-23, Springer, Berlin, Germany, 2014.

[3] B. Holmstedt, "Structure-activity relationships of the organophosphorus anticholinesterase agents," in Cholinesterases and Anticholinesterase Agents, pp. 428-485, Springer, Berlin, Germany, 1963.

[4] A. Suryanarayanan, "Acetylcholine," in Encyclopedia of Toxicology, pp. 49-50, Academic Press, Cambridge, MA, USA, 2014.

[5] J. L. Willems, J. P. Langenberg, A. G. Verstraete et al., "Plasma concentrations of pralidoxime methylsulphate in organophosphorus poisoned patients," Archives of Toxicology, vol. 66, no. 4, pp. 260-266, 1992.

[6] T. Suzuki, "Sarin poisoning in Tokyo subway," Lancet, vol. 345, no. 8955, pp. 980-981, 1995.

[7] R. Besser, L. S. Weilemann, and U. Schollmeyer, K. R. Szinicz and P. Eyer, "Synaptic transmisson during pesticide poisoning: the neuromuscular block," in Role of oximes in the Treatment of Anticholinesterase Agent Poisoning, pp. 19-31, Spektrum, Akademischer Verlag, Heidelberg, Germany, 1996.

[8] F. R. Sidell, T. E. Takafuji, F. R. Sidell, and D. R. Franz, "Nerve agents," in Textbook of Military Medicine, Office of the Surgeon General at TMM Publications, Washington, DC, USA, 2004.

[9] F. He, H. Xu, F. Qin, L. Xu, J. Huang, and X. He, "Intermediate myasthenia syndrome following acute organophosphates poisoning--an analysis of 21 cases," Human \& Experimental Toxicology, vol. 17, no. 1, pp. 40-45, 1998.

[10] K. Kuca, D. Jun, and K. Musilek, "Structural requirements of acetylcholinesterase reactivators," Mini-Reviews in Medicinal Chemistry, vol. 6, no. 3, pp. 269-277, 2006.

[11] G. A. Petroianu, K. Arafat, S. M. Nurulain, K. Kuca, and J. Kassa, "In vitro oxime reactivation of red blood cell acetylcholinesterase inhibited by methyl-paraoxon," Journal of Applied Toxicology, vol. 27, no. 2, pp. 168-175, 2007.
[12] J. A. Cohen and M. G. Warringa, "Purification and properties of dialkylfluorophosphatase," Biochimica et Biophysica Acta, vol. 26, no. 1, pp. 29-39, 1957.

[13] A. F. Childs, D. R. Davies, A. L. Green, and J. P. Rutland, "The reactivation by oximes and hydroxamic acids of cholinesterase inhibited by organo-phosphorus compounds," British Journal of Pharmacology and Chemotherapy, vol. 10, no. 4, pp. 462-465, 1955.

[14] I. B. Wilson and S. Ginsburg, "Reactivation of acetylcholinesterase inhibited by alkylphosphates," Archives of Biochemistry and Biophysics, vol. 54, no. 2, pp. 569-571, 1955.

[15] I. B. Wilson, "Acetylcholinesterase* XIII. Reactivation of alkyl phosphate-inhibited enzyme," Journal of Biological Chemistry, vol. 199, 1952.

[16] G. Mercey, "Reactivators of acetylcholinesterase inhibited by organophosphorus nerve agents," Accounts of Chemical Research, vol. 45, no. 5, pp. 756-766, 2012.

[17] G. Johnson and S. Moore, "The peripheral anionic site of acetylcholinesterase: structure, functions and potential role in rational drug design," Current Pharmaceutical Design, vol. 12, no. 2, pp. 217-225, 2006.

[18] D. D. Johnson and W. C. Stewart, "The effects of atropine, pralidoxime, and lidocaine on nerve--muscle and respiratory function in organophosphate-treated rabbits," Canadian Journal of Physiology and Pharmacology, vol. 48, no. 9, pp. 625-630, 1970.

[19] L. Harris and D. Stitcher, "Protection against diisopropylfluorophosphate intoxication by pyridostigmine and physostigmine in combination with atropine and mecamylamine," Naunyn-Schmiedeberg's Archives of Pharmacology, vol. 327, no. 1, pp. 64-69, 1984.

[20] A. Galosi, A. Deljac, V. Deljac, Z. Binenfeld, and M. Makisimovic, "ChemInform abstract: reactivators of acetylcholinesterase inhibited by organophosphorus compounds. Imidazole derivatives," ChemInform, vol. 19, no. 32, 1988.

[21] T. O. N Masuda, M. Takatsu, and H. Morinari, "Sarin poisoning in Tokyo subway-PubMed," Lancet, vol. 345, no. 8962, p. 1446, 1995.

[22] F. R. Sidell, F. R. Newmark, and J. McDonough, S. D. Tuorinsky, "Nerve agents," in Medical Aspects of Chemical Warfare, pp. 155-219, Office of The Surgeon General United States Army and Borden Institute, Walter Reed Army Medical Center, Washington, DC, USA, 2008.

[23] M. Jokanović, "Pyridinium oximes in the treatment of poisoning with organophosphorus compounds," Handbook of Toxicology of Chemical Warfare Agents, pp. 1057-1070, Academic Press, Cambridge, MA, USA, Second edition, 2015.

[24] R. H. Inns and L. Leadbeater, "The efficacy of bispyridinium derivatives in the treatment of organophosphonate poisoning in the Guinea-pig," Journal of Pharmacy and Pharmacology, vol. 35, no. 7, pp. 427-433, 1983.

[25] I. Koplovitz and J. R. Stewart, "A comparison of the efficacy of HI6 and 2-PAM against soman, tabun, sarin, and VX in the rabbit," Toxicology Letters, vol. 70, no. 3, pp. 269-279, 1994.

[26] K. Musilek, D. Jun, J. Cabal, J. Kassa, F. Gunn-Moore, and K. Kuca, "Design of a potent reactivator of tabun-inhibited acetylcholinesterases synthesis and evaluation of (E)-1-(4carbamoylpyridinium)-4-(4-hydroxyiminomethylpyridinium)-but-2-ene dibromide (K203)," Journal of Medicinal Chemistry, vol. 50, 2007. 
[27] J. Kassa, J. Karasova, K. Musilek, and K. Kuca, “An evaluation of therapeutic and reactivating effects of newly developed oximes (K156, K203) and commonly used oximes (obidoxime, trimedoxime, HI-6) in tabun-poisoned rats and mice," Toxicology, vol. 243, no. 3, pp. 311-316, 2008.

[28] L. Gorecki, O. Soukup, T. Kucera et al., "Oxime K203: a drug candidate for the treatment of tabun intoxication," Archives of Toxicology, vol. 93, no. 3, pp. 673-691, 2019.

[29] R. Lo and B. Ganguly, "Can hydroxylamine be a more potent nucleophile for the reactivation of tabun-inhibited AChE than prototype oxime drugs? an answer derived from quantum chemical and steered molecular dynamics studies," Molecular BioSystems, vol. 10, no. 9, pp. 2368-2383, 2014.

[30] P. M. Lundy, M. G. Hamilton, T. W. Sawyer, and J. Mikler, "Comparative protective effects of HI-6 and MMB-4 against organophosphorous nerve agent poisoning," Toxicology, vol. 285, no. 3, pp. 90-96, 2011.

[31] P. Eyer, "HLö 7 dimethanesulfonate, a potent bispyridiniumdioxime against anticholinesterases," Archives of Toxicology, vol. 66, no. 9, pp. 603-621, 1992.

[32] J. G. Clement, "Central activity of acetylcholinesterase oxime reactivators," Toxicology and Applied Pharmacology, vol. 112, no. 1, pp. 104-109, 1992.

[33] F. Eyer, F. Worek, P. Eyer et al., "Obidoxime in acute organophosphate poisoning: 1-clinical effectiveness," Clinical Toxicology, vol. 47, no. 8, pp. 798-806, 2009.

[34] P. Eyer, "The role of oximes in the management of organophosphorus pesticide poisoning," Toxicological Reviews, vol. 22 , no. 3, pp. 165-190, 2003.

[35] M. Jokanovic and M. Prostran, "Pyridinium oximes as cholinesterase reactivators. structure-activity relationship and efficacy in the treatment of poisoning with organophosphorus compounds," Current Medicinal Chemistry, vol. 16, no. 17, pp. 2177-2188, 2009.

[36] F. Worek, H. Thiermann, and T. Wille, "Organophosphorus compounds and oximes: a critical review," Archives of Toxicology, vol. 94, no. 7, pp. 2275-2292, 2020.

[37] M. Eddleston, "Oximes in acute organophosphorus pesticide poisoning: a systematic review of clinical trials," QJM, vol. 95, no. 5 , pp. $275-283,2002$.

[38] J. Cabal, K. Kuča, and J. Kassa, "Specification of the structure of oximes able to reactivate tabun-inhibited acetylcholinesterase," Basic \& Clinical Pharmacology \& Toxicology, vol. 95, no. 2, pp. 81-86, 2004.

[39] S. Berend, A. L. Vrdoljak, B. Radic, and K. Kuca, "New bispyridinium oximes: in vitro and in vivo evaluation of their biological efficiency in soman and tabun poisoning," Chemico-Biological Interactions, vol. 175, no. 1-3, pp. 413416, 2008.

[40] U. Spöhrer, H. Thiermann, R. Klimmek, and P. Eyer, "Pharmacokinetics of the oximes HI 6 and HLö 7 in dogs after i.m. injection with newly developed dry/wet autoinjectors," Archives of Toxicology, vol. 68, no. 8, pp. 480-489, 1994.

[41] K. Kuca, J. Cabal, J. Kassa, D. Jun, and M. Hrabinová, “A comparison of the potency of the oxime HLö-7 and currently used oximes (HI-6, pralidoxime, obidoxime) to reactivate nerve agent-inhibited rat brain acetylcholinesterase by in vitro methods," Acta Medica, vol. 48, no. 2, pp. 81-86, 2005.

[42] N. V. Kokshareva, Medical Treatment of Intoxications and Decontamination of Chemical Agents in the Area of Terrorist Attack, Springer Science \& Business Media, Amsterdam, Netherlands, 2006.
[43] P. Eyer, B. Ladstetter, W. Schäfer, and J. Sonnenbichler, "Studies on the stability and decomposition of the Hagedorn-oxime HLö 7 in aqueous solution," Archives of Toxicology, vol. 63, no. 1, pp. 59-67, 1989.

[44] F. L. Hsu, "Synthesis and molecular properties of nerve agent reactivator HLö-7 dimethanesulfonate," ACS Medicinal Chemistry Letters, vol. 10, no. 5, pp. 761-766, 2019.

[45] E. Reiner and V. S. Rudolf, "Pyridinium, imidazolium and quinuclidinium compounds: toxicity and antidotal effects against the nerve agents Tabun and Soman-PubMed," Archives of Industrial Hygiene and Toxicology, vol. 57, no. 2, pp. 171-179, 2006.

[46] W. K. Berry and D. R. Davies, "Factors influencing the rate of "aging" of a series of alkyl methylphosphonyl-acetylcholinesterases," Biochemical Journal, vol. 100, no. 2, p. 572, 1966.

[47] H. D. Crone, "Can allosteric effectors of acetylcholinesterase control the rate of ageing of the phosphonylated enzyme?" Biochemical Pharmacology, vol. 23, no. 2, pp. 460-463, 1974.

[48] Y. Bourne, P. Taylor, Z. Radić, and P. Marchot, "Structural insights into ligand interactions at the acetylcholinesterase peripheral anionic site," The EMBO Journal, vol. 22, no. 1, p. 1, 2003.

[49] S. H. Sterri, "Effect of imidazoles and $\mathrm{pH}$ on aging of phosphylated acetylcholinesterase," Biochemical Pharmacology, vol. 26, no. 7, pp. 656-658, 1977.

[50] Q. Zhuang, "Efforts toward treatments against aging of organophosphorus-inhibited acetylcholinesterase," Annals of the New York Academy of Sciences, vol. 1374, no. 1, pp. 94-104, 2016.

[51] J. J. Topczewski and D. M. Quinn, "Kinetic assessment of $\mathrm{N}$-methyl-2-methoxypyridinium species as phosphonate anion methylating agents," Organic Letters, vol. 15, no. 5, pp. 1084-1087, 2013.

[52] P. Blumbergs, "Alkylating agents containing a quaternary nitrogen group," Journal of Organic Chemistry, vol. 34, no. 12 , pp. 4065-4070, 2002.

[53] G. M. Steinberg, C. N. Lieske, R. Boldt, J. C. Goan, and H. E. Podall, "Model studies for the reactivation of aged phosphonylated acetylcholinesterase. Use of alkylating agents containing nucleophilic groups," Journal of Medicinal Chemistry, vol. 13, no. 3, pp. 435-446, 2002.

[54] B. A. Bakke, M. C. McIntosh, and K. D. Turnbull", "Improved alkylation and product stability in phosphotriester formation through quinone methide reactions with dialkyl phosphates," Journal of Organic Chemistry, vol. 70, no. 11, pp. 4338-4345, 2005.

[55] N. B. Chandar, R. Lo, and B. Ganguly, "Quantum chemical and steered molecular dynamics studies for one pot solution to reactivate aged acetylcholinesterase with alkylator oxime," Chemico-Biological Interactions, vol. 223, pp. 58-68, 2014.

[56] L. Gorecki, O. Gerlits, X. Kong et al., "Rational design, synthesis, and evaluation of uncharged, "smart" bis-oxime antidotes of organophosphate-inhibited human acetylcholinesterase," Journal of Biological Chemistry, vol. 295, no. 13, pp. 4079-4092, 2020.

[57] E. S. Rachaman, Y. Ashani, H. Leader et al., "Sugar-oximes, new potential antidotes against organophosphorus poisoning," Arzneimittelforschung, vol. 29, no. 6, 1979.

[58] E. Heldman, Y. Ashani, L. Raveh, and E. S. Rachaman, "Sugar conjugates of pyridinium aldoximes as antidotes against organophosphate poisoning," Carbohydrate Research, vol. 151, pp. 337-347, 1986. 
[59] G. E. Garcia, A. J. Campbell, J. Olson, D. Moorad-Doctor, and V. I. Morthole, "Novel oximes as blood-brain barrier penetrating cholinesterase reactivators," Chemico-Biological Interactions, vol. 187, no. 1-3, pp. 199-206, 2010.

[60] F. R. De Souza, D. R. Garcia, T. Cuya et al., "Molecular modeling study of uncharged oximes compared to HI-6 and 2-PAM inside human ache sarin and VX conjugates," ACS Omega, vol. 5, no. 9, pp. 4490-4500, 2020.

[61] M. N. Faiz Norrrahim, M. A. I. A. Razak, N. A. A. Shah et al., "Recent developments on oximes to improve the blood brain barrier penetration for the treatment of organophosphorus poisoning: a review," RSC Advances, vol. 10, no. 8, pp. 4465-4489, 2020.

[62] Y. J. Rosenberg, J. Wang, T. Ooms et al., "Post-exposure treatment with the oxime RS194B rapidly reactivates and reverses advanced symptoms of lethal inhaled paraoxon in macaques," Toxicology Letters, vol. 293, pp. 229-234, 2018.

[63] T. Zorbaz, D. Malinak, K. Kuca, K. Musilek, and Z. Kovarik, "Butyrylcholinesterase inhibited by nerve agents is efficiently reactivated with chlorinated pyridinium oximes," ChemicoBiological Interactions, vol. 307, pp. 16-20, 2019.

[64] F. R. Sidell, S. Somani, "Clinical considerations in nerve agent intoxication," in Chemical Warfare Agents, p. 181, Academic Press, New York, NY, USA, 1992.

[65] Z. Wei, Y. Q. Liu, Y. A. Wang et al., "Novel nonquaternary reactivators showing reactivation efficiency for somaninhibited human acetylcholinesterase," Toxicology Letters, vol. 246, pp. 1-6, 2016.

[66] N. Vanova, A. Honja, J. Pejchal et al., "Determination of K869, a novel oxime reactivator of acetylcholinesterase, in rat body fluids and tissues by liquid-chromatography methods: pharmacokinetic study," Journal of Pharmaceutical Sciences, vol. 110, no. 4, pp. 1842-1852, 2021.

[67] T. C. Marrs, P. Rice, and J. A. Vale, "The role of oximes in the treatment of nerve agent poisoning in civilian casualties," Toxicological Reviews, vol. 25, no. 4, pp. 297-323, 2006.

[68] H. Kharel, N. B. Pokhrel, R. Ghimire, and Z. Kharel, "The efficacy of pralidoxime in the treatment of organophosphate poisoning in humans: a systematic review and meta-analysis of randomized trials," Cureus, vol. 12, no. 3, 2020.

[69] M. A. Dunn and B. E. Hackley, F. R. Sidell, E. T. Takafuji, D. R. Franz, and R. Zajtchuk, "Pretreatment for nerve agent exposure," in Medical Aspects of Chemical and Biological Warfare, pp. 181-196, U.S. Department of the Army Office of the Surgeon General and Borden Institute, Washington, DC, USA, 1997.

[70] E. J. Mew, P. Padmanathan, F. Konradsen et al., "The global burden of fatal self-poisoning with pesticides 2006-15: systematic review," Journal of Affective Disorders, vol. 219, pp. 93-104, 2017.

[71] M. Eddleston, "Novel clinical toxicology and pharmacology of organophosphorus insecticide self-poisoning," Annual Review of Pharmacology and Toxicology, vol. 59, pp. 341-360, 2019.

[72] A. Blumenberg, R. Benabbas, I. S. De Souza et al., "Utility of 2-pyridine aldoxime methyl chloride (2-PAM) for acute organophosphate poisoning: a systematic review and metaanalysis," Journal of Medical Toxicology, vol. 14, no. 1, pp. 91-98, 2018.

[73] M. Eddleston, N. A. Buckley, P. Eyer, and A. H. Dawson, "Management of acute organophosphorus pesticide poisoning," The Lancet, vol. 371, pp. 597-607, 2008.
[74] J. Davies, D. Roberts, P. Eyer, N. Buckley, and M. Eddleston, "Hypotension in severe dimethoate self-poisoning," Clinical Toxicology, vol. 46, no. 9, pp. 880-884, 2008.

[75] P. Jacquet, L. Poirier, D. Daudé, and E. Chabrière, "Intoxication aux organophosphorés: vers des traitements enzymatiques," Annales Pharmaceutiques Françaises, vol. 77, no. 5, pp. 349-362, 2019.

[76] S. V. Lushchekina, L. M. Schopfer, B. L. Grigorenko et al., "Optimization of cholinesterase-based catalytic bioscavengers against organophosphorus agents," Frontiers in Pharmacology, vol. 9, p. 211, 2018.

[77] J. V. Peter, J. L. Moran, K. Pichamuthu, and B. Chacko, "Adjuncts and alternatives to oxime therapy in organophosphate poisoning-is there evidence of benefit in human poisoning? a review," Anaesthesia \& Intensive Care, vol. 363 pages, 2008.

[78] R. K. Gordon, S. R. Feaster, A. J. Russell et al., "Organophosphate skin decontamination using immobilized enzymes," Chemico-Biological Interactions, vol. 119-120, pp. 463-470, 1999.

[79] M. Jokanovi, "Biotransformation of organophosphorus compounds," Toxicology, vol. 166, no. 3, pp. 139-160, 2001.

[80] S. Vikram, Biotechnology: Concepts, Methodologies, Tools, and Applications: Concepts, Google Books. IGI Global, Hershey, PA, USA, 2019.

[81] G. L. Lamoureux and D. G. Rusness, "Synergism of diazinon toxicity and inhibition of diazinon metabolism in the house fly by tridiphane: inhibition of glutathione S-transferase activity," Pesticide Biochemistry and Physiology, vol. 27, no. 3, pp. 318-329, 1987.

[82] C.-N. Sun, S.-Y. Huang, N.-T. Hu, and W.-Y. Chung, "Glutathione $S$ transferases and insect resistance to insecticides," in Biochemical Sites of Insecticide Action and Resistance, pp. 239-254, Springer, Berlin, Germany, 2001.

[83] K. Fujioka and J. E. Casida, "Glutathione S-transferase conjugation of organophosphorus pesticides yields S-phospho-, S-aryl-, and S-alkylglutathione derivatives," Chemical Research in Toxicology, vol. 20, no. 8, pp. 1211-1217, 2007.

[84] L. Ezemonye and I. Tongo, "Sublethal effects of endosulfan and diazinon pesticides on glutathione-S-transferase (GST) in various tissues of adult amphibians (Bufo regularis)," Chemosphere, vol. 81, no. 2, pp. 214-217, 2010.

[85] K. Yamamoto and N. Yamada, "Identification of a diazinonmetabolizing glutathione S-transferase in the silkworm, Bombyx mori," Scientific Reports, vol. 61, no. 1, pp. 1-9, 2016.

[86] K. Yamamoto, A. Higashiura, A. Hirowatari et al., "Characterisation of a diazinon-metabolising glutathione S-transferase in the silkworm Bombyx mori by X-ray crystallography and genome editing analysis," Scientific Reports, vol. 8, no. 1, pp. 1-10, 2018.

[87] M. Eddleston, R. E. Clutton, M. Taylor et al., "Efficacy of an organophosphorus hydrolase enzyme (OpdA) in human serum and minipig models of organophosphorus insecticide poisoning," Clinical Toxicology, vol. 58, no. 5, pp. 397-405, 2020.

[88] R. N. Brogden, T. M. Speight, and G. S. Avery, "Streptokinase: a review of its clinical pharmacology, mechanism of action and therapeutic uses," Drugs, vol. 5, no. 5, pp. 357-445, 1973.

[89] S. D. Kirby, J. R. Norris, J. Richard Smith, B. J. Bahnson, and D. M. Cerasoli, "Human paraoxonase double mutants hydrolyze V and G class organophosphorus nerve agents," Chemico-Biological Interactions, vol. 203, no. 1, pp. 181-185, 2013. 
[90] T.-C. Cheng, S. P. Harvey, and A. N. Stroup, "Purification and properties of a highly active organophosphorus acid anhydrolase from alteromonas undina," Applied and Environmental Microbiology, vol. 59, 1993.

[91] Z. Sarlak, K. Khosravi-Darani, M. Rouhi, F. Garavand, R. Mohammadi, and M. R. Sobhiyeh, "Bioremediation of organophosphorus pesticides in contaminated foodstuffs using probiotics," Food Control, vol. 126, p. 108006, 2021.

[92] Y. Ashani and S. Pistinner, "Estimation of the upper limit of human butyrylcholinesterase dose required for protection against organophosphates toxicity: a mathematically based toxicokinetic model," Toxicological Sciences, vol. 77, no. 2, pp. 358-367, 2004.

[93] A. Saxena, W. Sun, J. M. Fedorko, I. Koplovitz, and B. P. Doctor, "Prophylaxis with human serum butyrylcholinesterase protects Guinea pigs exposed to multiple lethal doses of soman or VX," Biochemical Pharmacology, vol. 81, no. 1, pp. 164-169, 2011.

[94] R. L. Lundblad and R. A. Bradshaw, "Applications of sitespecific chemical modification in the manufacture of biopharmaceuticals: I. an overview," Biotechnology and Applied Biochemistry, vol. 26, no. 3, pp. 143-151, 1997.

[95] K. Quester, K. Juarez-Moreno, I. Secundino et al., "Cytochrome P450 bioconjugate as a nanovehicle for improved chemotherapy treatment," Macromolecular Bioscience, vol. 17, no. 5, 2017

[96] D. E. Lenz, D. Yeung, J. R. Smith, R. E. Sweeney, L. A. Lumley, and D. M. Cerasoli, "Stoichiometric and catalytic scavengers as protection against nerve agent toxicity: a mini review," Toxicology, vol. 233, no. 1-3, pp. 31-39, 2007.

[97] L. Raveh, J. Grunwald, D. Marcus, Y. Papier, E. Cohen, and Y. Ashani, "Human butyrylcholinesterase as a general prophylactic antidote for nerve agent toxicity. In vitro and in vivo quantitative characterization," Biochemical Pharmacology, vol. 45, no. 12, pp. 2465-2474, 1993.

[98] D. E. Lenz, D. M. Maxwell, I. Koplovitz et al., "Protection against soman or VX poisoning by human butyrylcholinesterase in Guinea pigs and cynomolgus monkeys," Chemico-Biological Interactions, vol. 157-158, pp. 205-210, 2005.

[99] D. M. Cerasoli, S. J. Armstrong, T. E. Reeves et al., "Butyrylcholinesterase, a stereospecific in vivo bioscavenger against nerve agent intoxication," Biochemical Pharmacology, vol. 171, p. 113670, 2020.

[100] K. Alejo-González, E. Hanson-Viana, and R. VazquezDuhalt, "Enzymatic detoxification of organophosphorus pesticides and related toxicants," Journal of Pesticide Science, vol. 43, no. 1, p. 1, 2018.

[101] F. M. Buratti and E. Testai, "Malathion detoxification by human hepatic carboxylesterases and its inhibition by isomalathion and other pesticides," Journal of Biochemical and Molecular Toxicology, vol. 19, no. 6, pp. 406-414, 2006.

[102] R. C. Gupta and J. W. Crissman, W. M. Haschek, C. G. Rousseaux, and M. A. Wallig, "Agricultural chemicals," in Haschek and Rousseaux's Handbook of Toxicologic Pathology, pp. 1349-1372, Elsevier, Amsterdam, Netherlands, 2013.

[103] P. Jacquet, D. Daudé, J. Bzdrenga, P. Masson, M. Elias, and E. Chabrière, "Current and emerging strategies for organophosphate decontamination: special focus on hyperstable enzymes," Environmental Science \& Pollution Research, vol. 23, no. 9, pp. 8200-8218, 2016.
[104] L. Merone, L. Mandrich, M. Rossi, and G. Manco, "A thermostable phosphotriesterase from the archaeon Sulfolobus solfataricus: cloning, overexpression and properties," Extremophiles, vol. 9, no. 4, pp. 297-305, 2005.

[105] I. Horne, T. D. Sutherland, R. L. Harcourt, R. J. Russell, and J. G. Oakeshott, "Identification of an opd (organophosphate degradation) gene in an agrobacterium isolate," Applied and Environmental Microbiology, vol. 68, no. 7, pp. 3371-3376, 2002.

[106] T. Wille, C. Scott, H. Thiermann, and F. Worek, "Detoxification of G-and V-series nerve agents by the phosphotriesterase OpdA," Biocatalysis and Biotransformation, vol. 30, no. 2, pp. 203-208, 2012.

[107] T. Sutherland, R. Russell, and M. Selleck, "Using enzymes to clean up pesticide residues," Pesticide Outlook, vol. 13, no. 4, pp. 149-151, 2002.

[108] M. A. Sogorb and E. Vilanova, "Enzymes involved in the detoxification of organophosphorus, carbamate and pyrethroid insecticides through hydrolysis," Toxicology Letters, vol. 128, no. 1-3, pp. 215-228, 2002.

[109] P. C. Tsai, A. Bigley, Y. Li et al., "Stereoselective hydrolysis of organophosphate nerve agents by the bacterial phosphotriesterase," Biochemistry, vol. 49, no. 37, pp. 7978-7987, 2010.

[110] A. Saxena, W. Sun, C. Luo et al., "Bioscavenger for protection from toxicity of organophosphorus compounds," Journal of Molecular Neuroscience, vol. 30, no. 1-2, pp. 145-147, 2006.

[111] Z. Kovarik, M. Katalinić, G. Sinko et al., "Pseudo-catalytic scavenging: searching for a suitable reactivator of phosphorylated butyrylcholinesterase," Chemico-Biological Interactions, vol. 187, no. 1-3, pp. 167-171, 2010.

[112] N. Maček Hrvat, S. Žunec, P. Taylor, Z. Radić, and Z. Kovarik, "HI-6 assisted catalytic scavenging of VX by acetylcholinesterase choline binding site mutants," ChemicoBiological Interactions, vol. 259, pp. 148-153, 2016.

[113] R. K. Sit, V. V. Fokin, G. Amitai, K. Barry Sharpless, P. Taylor, and Z. Radic, "Imidazole aldoximes effective in assisting butyrylcholinesterase catalysis of organophosphate detoxification," Journal of Medicinal Chemistry, vol. 57, no. 4, pp. 1378-1389, 2014.

[114] Z. Kovarik, N. Maček Hrvat, M. Katalinić et al., "No title," Chemical Research in Toxicology, vol. 28, pp. 1036-1044, 2015.

[115] M. J. Hatfield, R. A. Umans, J. L. Hyatt et al., "General detoxifying 981 enzymes," Chemico-Biological Interactions, vol. 259, 2016.

[116] C. L. Cadieux, H. Wang, Y. Zhang et al., "Probing the activity of a non-oxime reactivator for acetylcholinesterase inhibited by organophosphorus nerve agents," Chemico-Biological Interactions, vol. 259, pp. 133-141, 2016.

[117] M. C. De Koning, G. Horn, F. Worek, and M. van Grol, "Discovery of a potent non-oxime reactivator of nerve agent inhibited human acetylcholinesterase," European Journal of Medicinal Chemistry, vol. 157, pp. 151-16, 2018.

[118] A. A. De Castro, L. C. Assis, F. V. Soares et al., "Trends in the recent patent literature on cholinesterase reactivators (2016-2019)," Biomolecules, vol. 10, no. 3, p. 436, 2020.

[119] L. Gorecki, J. Korabecny, K. Musilek et al., "Progress in acetylcholinesterase reactivators and in the treatment of organophosphorus intoxication: a patent review (2006-2016)," Expert Opinion on Therapeutic Patents, vol. 27, no. 9, pp. 971-985, 2017. 
[120] P. J. Lein, M. J. J. Meerhoff, G. F. S. M. Vester, P. Hesseling, S. D. Klaassen, and A. S. Cornelissen, "No title," Neurotoxicology, vol. 68, pp. 167-176, 2018.

[121] G. Amitai, R. Gez, L. Raveh, N. Bar-Ner, E. Grauer, and S. Chapman, "Novel bifunctional hybrid small molecule scavengers for mitigating nerve agents toxicity," ChemicoBiological Interactions, vol. 259, no. Pt B, pp. 187-220, 2016.

[122] S. Letort, M. Bosco, B. Cornelio et al., "Structure-efficiency relationships of cyclodextrin scavengers in the hydrolytic degradation of organophosphorus compounds," Journal of Organic Chemistry, vol. 13, pp. 417-427, 2017.

[123] A. Kranawetvogl, S. Muller, S. Kubik et al., "Elimination kinetics and molecular reaction mechanisms of cyclosarin (GF) by an oxime substituted beta-cyclodextrin derivative in vitro," Toxicology Letters, vol. 239, pp. 41-52, 2015.

[124] A. Bierwisch, M. Koller, F. Worek, and S. Kubik, "Pathways of reactions between neurotoxic organophosphorus compounds and oximes or hydroxamic acids," European Journal of Organic Chemistry, vol. 2016, no. 35, 2016.

[125] P. Masson and F. Nachon, "Cholinesterase reactivators and bioscavengers for pre-and post-exposure treatments of organophosphorus poisoning," Journal of Neurochemistry, vol. 142, pp. 26-40, 2017.

[126] J. B. G. Filho, C. G. O. Bruziquesi, R. D. F. Rios et al., "Selective visible-light-driven toxicity breakdown of nerve agent simulant methyl paraoxon over a photoactive nanofabric," Applied Catalysis B: Environmental, vol. 285, p. 119774, 2021. 